Article

\title{
Nitride-Coated and Anodic-Oxidized Titanium Promote a Higher Fibroblast and Reduced Streptococcus gordonii Proliferation Compared to the Uncoated Titanium
}

\author{
Khrystyna Zhurakivska ${ }^{1}\left(\mathbb{D}\right.$, Nagaia Ciacci $^{2}$, Giuseppe Troiano ${ }^{1}{ }^{\circledR}$, Vito Carlo Alberto Caponio ${ }^{1}$, \\ Roberto Scrascia ${ }^{1}$, Lucia Pallecchi ${ }^{2}$, Lorenzo Lo Muzio ${ }^{1}{ }^{D}$ and Fabio Arena ${ }^{1, *}$ \\ 1 Department of Clinical and Experimental Medicine, Foggia University, Via Antonio Gramsci, \\ 89, 71122 Foggia, Italy; khrystyna.zhurakivska@unifg.it (K.Z.); giuseppe.troiano@unifg.it (G.T.); \\ vitocarlo.caponio@unifg.it (V.C.A.C.); roberto.scrascia@gmail.com (R.S.); Lorenzo.lomuzio@unifg.it (L.L.M.) \\ 2 Department of Medical Biotechnologies, University of Siena, Banchi di Sotto, 55, 53100 Siena, Italy; \\ nagaia.ciacci@unisi.it (N.C.); lucia.pallecchi@unisi.it (L.P.) \\ * Correspondence: fabio.arena@unifg.it
}

Received: 21 October 2020; Accepted: 10 November 2020; Published: 12 November 2020

check for updates

\begin{abstract}
Titanium shows optimal biocompatibility properties; however, its gray color may be a limit for aesthetic results of dental rehabilitations. Some surface treatments that change the color of the material have been proposed. The aim of this study is to, in vitro, investigate the biocompatibility of the surfaces subjected to titanium nitride (NiT) coating and anodic-oxidized (AO) treatment and their propensity to impair bacterial proliferation. The viability of primary human gingival fibroblasts (HGFs) has been evaluated through a methyl thiazolyl tetrazolium (MTT) assay in three experimental groups: uncoated titanium (UNCOATED), titanium nitride (NiT)-coated surface, and anodic-oxidized (AO) titanium. Bacterial proliferation experiments were performed using a Streptococcus gordonii clinical isolate in contact with the three different above-mentioned materials. The treated surfaces (NiT and $\mathrm{AO}$ ) showed a significantly higher fibroblast proliferation than the uncoated titanium alloy $(p<0.05)$. In contrast, Streptococcus gordonii growth was significantly higher on the untreated titanium $(p<0.05)$.
\end{abstract}

Keywords: titanium-nitride; anodic-oxidized; surface coating; biocompatibility; Streptococcus gordonii

\section{Introduction}

Dental implants are commonly used in dentistry in case of prosthetic rehabilitation of missing teeth. They act as an artificial root for the retention of overlying full or partial prosthesis. A key element in implant-supported restorations is represented by the abutment, a connecting element that is able to link fixture and dental prosthesis [1].

Long term success of dental implant restoration depends both on osseointegration, documented almost with 50 years of clinical practice [1,2], and soft tissue healing around the abutment [3]. As far as we know, the attachment of soft tissue around the abutment acts as a seal, preventing bacterial invasion into underlying bone [3,4]. Because the soft tissue attachment plays a primary role for the long-term outcome of the dental implant, abutment material should have excellent biological and physical properties [5].

Titanium represents the most commonly used material for dental implant abutment manufacture, because of its biocompatibility, corrosion resistance, mechanical properties, low immunogenic potential, and resistance to plaque accumulation [6]. 
Surface Coating of dental implants has been deeply investigated, finding enhanced osseointegration properties deriving from some treatments [7]. Similarly, a variety of surface coatings have been proposed to improve biological interaction between implant abutment and oral soft tissues [8].

One of the drawbacks of titanium abutments is represented by their gray color, which may shine through thin mucosa and bone, disturbing the esthetical outcome of prosthetic rehabilitation [9].

To overcome this problem, some surface treatments, such as coating or anodic-oxidized immobilization, have been developed [10]. In both the superficial treatments, abutments could achieve a lighter color than titanium alloy $\mathrm{V}$, preventing dark color transmission through gingiva [11]. Following these treatments, the typical gray of titanium turns into yellow in the case of titanium nitride (NiT) coating and green in the case of anodic-oxidized (AO) treatment.

Bacterial infections are still one of the major causes of implant failure [12]. Streptococcus gordonii is a member of the commensal oral microbiota that has been involved in early colonization of metal surfaces, providing an attachment substrate for colonization and biofilm accretion by potential pathogens, such as Porphyromonas gingivalis, one of possible pathogens responsible for peri-implantitis [13-15].

The study purpose is to investigate, in vitro, the biological behavior of three different surfaces: titanium $\mathrm{NiT}, \mathrm{AO}$, and uncoated titanium. In particular, it aims to assess differences in (i) primary human gingival fibroblast (HGF) proliferation and (ii) Streptococcus gordonii growth.

\section{Results}

\subsection{Fibroblasts Metabolic Activity and Proliferation}

The results of the methyl thiazolyl tetrazolium (MTT) test provided data on biocompatibility of the surfaces in terms of viability of fibroblasts seeded on the disks of three experimental groups. Figure 1 summarizes obtained results at three time points $(24,48$, and $72 \mathrm{~h}$ ), revealing significant differences between the treated surfaces ( $\mathrm{NiT}$ and $\mathrm{AO})$ and the uncoated titanium $(p<0.05)$. On the contrary, no difference emerged between the titanium nitride (NiT) or anodic-oxidized (AO) treatment in terms of cellular proliferation ( $p=0.689, p=0.985$, and $p=0.3049$, respectively for $24 \mathrm{~h}, 48 \mathrm{~h}$, and $72 \mathrm{~h}$ ).

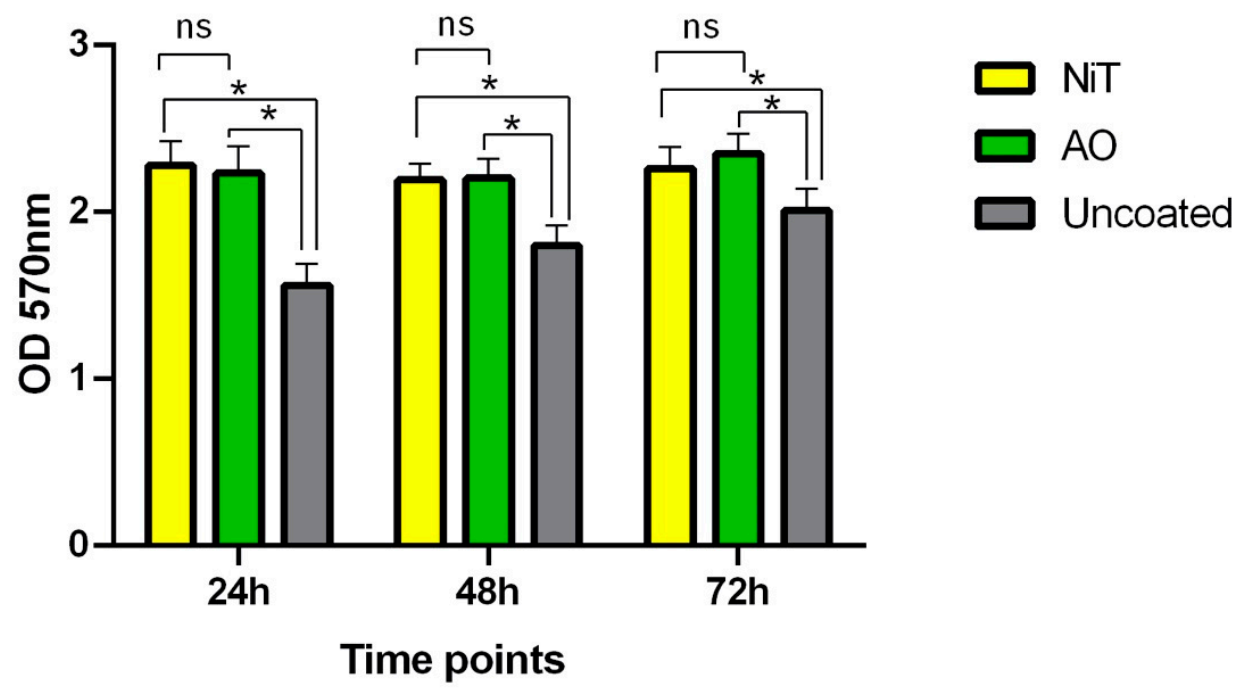

Figure 1. The methyl thiazolyl tetrazolium (MTT) assay of human gingival fibroblasts (HGFs) cultured on the investigated surfaces, measured at three timepoints $(24,48$, and $72 \mathrm{~h})$. ns: no statistically significant difference; ${ }^{*} p<0.05$.

\subsection{Streptococcus Gordonii Growth}

The analyzed Streptococcus gordonii was able to form colonies on all three studied materials. Statistically significant differences in the amount of bacterial formation were found among groups. 
In particular, the number of Streptococcus gordonii viable cells, expressed in colony-forming unit (CFU) per disk recovered from biofilm formed on $\mathrm{NiT}$ and $\mathrm{AO}$ was significantly lower compared to uncoated titanium disks $(p<0.05)$ (Figure 2). In addition, the direct comparison between NiT and AO revealed that $\mathrm{NiT}$ showed the lowest amount of bacterial formation, although results were close to the threshold of statistical significance $(p=0.061)$.

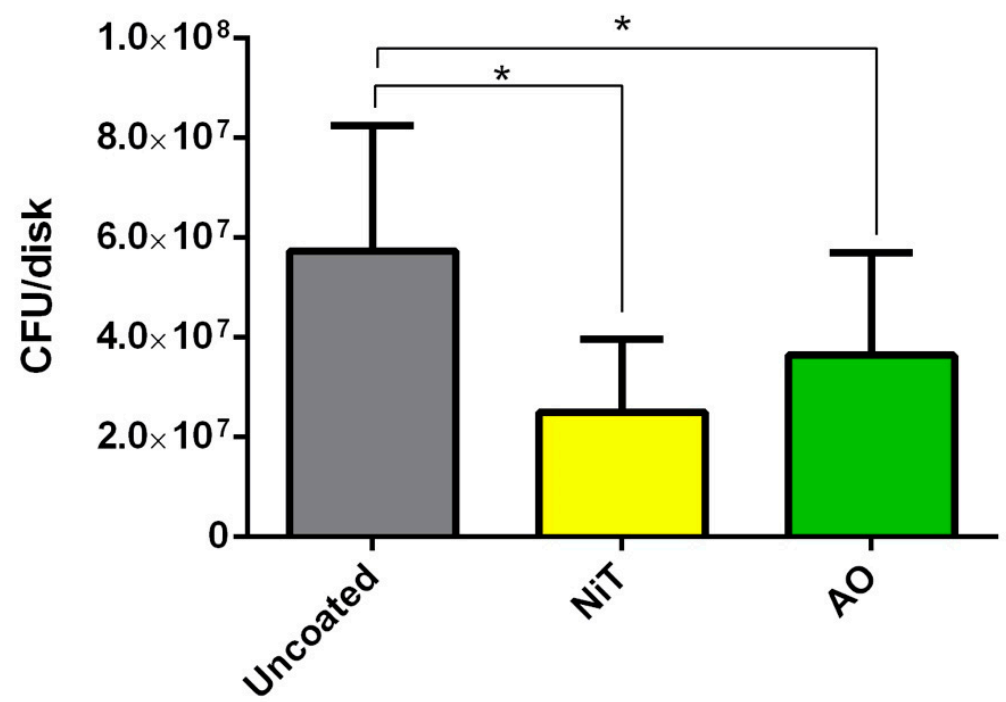

Figure 2. Streptococcus gordonii viable cells (expressed in CFU/disk) recovered from bacterial plaque formed on uncoated titanium, NiT, and AO. ${ }^{*} p<0.05$.

\section{Discussion}

The success of the long-term survival of a dental implant can only be achieved by an excellent integration of the implant with both hard and soft tissues of the oral cavity. While the main requirement of the dental implant fixture is its osseointegration capacity [1,2], the implant abutment must meet the requirements of both biocompatibility and aesthetics in its interface with gingival tissues [16]. Since the introduction of dental implantology, many materials have been proposed for the fabrication of dental abutments, starting with titanium, dental ceramics, or titanium surface treatments in order to better meet the aesthetic requirements, which are very relevant in some clinical situations. Among these, nitride coating and anodic-oxidation of the titanium surface allow us to obtain a change in color of the material, which, from the dark gray of the untreated titanium, turns to yellow-gold or green, respectively, after the specific surface treatment. However, beyond a better aesthetic result, the abutment surface must maintain maximum biocompatibility with oral tissues, minimizing bacterial adhesion and proliferation. In this regard, the present study aimed to investigate how three different surfaces (NiT, AO, and untreated titanium) influence fibroblast proliferation and bacterial growth when in contact in vitro. The experiments resulted in a significantly better proliferation of human gingival fibroblasts in contact with the treated surfaces, compared to the uncoated titanium, at every timepoint observation. Such results are consistent with the previous researches available in the literature $[8,11,17]$. No significant difference emerged from the comparison between the NiT and AO groups. Similarly, a recent study comparing uncoated Ti6Al4V, anodized and coated with titanium nitride or zirconium nitride abutments, found a superimposable fibroblasts adhesion and proliferation on all the surfaces. [18]

From a clinical point of view, a high compatibility with the gingival fibroblasts ensures a better mucous seal around the implant fixture and therefore a better barrier for protection of the underlying hard tissue structures and the implant itself [19].

Another factor investigated in this study was referred to the bacterial colony formations on the treated surfaces. 
Streptococcus gordonii is an early bacterial colonizer, known to play a crucial role in facilitating bacterial adhesion of middle colonizers (Fusobacterium nucleatum) and late colonizers (Porphyromonas gingivalis) $[13-15,20,21]$. The accumulation of bacterial plaque on the abutment surface has negative consequences, including inflammation, which, in the long run, can lead to implant loss. For this reason, the micro- and macroscopic characteristics of the surface must be such as to minimize bacterial adhesion. Since Streptococcus gordonii has been demonstrated to be fundamental for the initial colonization of abutment and dental surfaces by other bacterial species [13], its growth on investigated surfaces was evaluated. In our bacterial formation model, Streptococcus gordonii growth (number of viable cells recovered per disks) was notably lower on the $\mathrm{NiT}$ and AO surfaces than on the untreated titanium. Furthermore, in the direct comparison between the treated groups, NiT showed the lowest amount of bacterial proliferation, although results were close to the threshold of statistical significance. From the available studies, in which several bacterial species were investigated, including Streptococcus salivarius, S. sanguinis, S. mutans, S. sobrinus, and S. oralis, it emerged that biofilm formation was reduced on zirconium nitride surfaces and titanium nitride surfaces compared to untreated titanium [18]. For this purpose, some new materials, such as silicon nitride, have been proposed, showing better mechanical performance and antibacterial properties [22].

Obtained results encourage further investigations in order to better understand the biologic and clinical behaviors of such different materials.

The limitations of the study regard a limited number of investigated surfaces, as well as the bacterial species involved in the experiments. Furthermore, the experimental conditions do not reproduce the oral environment, where the biological conditions are peculiar. Therefore, surely, further investigations must be conducted, taking into account these considerations.

\section{Materials and Methods}

Three types of surfaces have been analyzed in this in vitro study: uncoated machined titanium alloy (UNCOATED), NiT-coated surface, and AO titanium. High disks at 8 and $5 \mathrm{~mm}$ diameter were manufactured by RHEIN 83 S.R.L. The nitriding process of coating was accomplished using the physical vapor deposition (PVD) method. Anodization was performed by applying a current of $2.2 \mathrm{~A}$ at a voltage of $62.8 \mathrm{~V}$ in a $5 \%$ phosphoric acid solution for $10 \mathrm{~min}$.

\subsection{Cell Culture and MTT Assay}

Primary human gingival fibroblasts (HGFs) were purchased from ATCC ${ }^{\circledR}$ PCS-201-018 ${ }^{\mathrm{TM}}$. The cells were cultured in fibroblast basal medium (ATCC ${ }^{\circledR}$ PCS-201-030 ${ }^{\mathrm{TM}}$ ) until confluence. The cells were then harvested using Trypsin treatment and seeded in 24 well-plates containing the experimental disks. In particular, $500 \mu \mathrm{L}$ of fibroblast basal medium, containing $1 \times 105$ cells, were put in each well, containing a disk. Three disks per experimental Group (UNCOATED, NiT, AO), provided by Rhein 83 s.r.l. (Bologna, Italy), were used in each plate. In the free wells, sterile phosphate buffered saline (PBS) was added to maintain humidity. The plates were then incubated at $37{ }^{\circ} \mathrm{C}$ with $5 \% \mathrm{CO}_{2}$. The evaluation of cell viability on the experimental disks was performed at three time points $(24,48$, and $72 \mathrm{~h}$ ). For this purpose, at each time point, the disks were transferred in empty wells, $500 \mu \mathrm{L}$ of new growth medium was added, and a methyl thiazolyl tetrazolium (MTT) assay [23] was performed. The MTT assay evaluated the activity of mitochondrial reductase through the conversion of the water-soluble yellow dye MTT (3-(4,5-dimethylthiazol-2-yl)-2,5-diphenyltetrazolium bromide) to an insoluble purple formazan. The last dye was then solubilized and the concentration was determined by optical density at $570 \mathrm{~nm}$. All data were obtained in three independent experiments.

\subsection{Biofilm Formation Experiments}

The bacterial strain used in this study was a Streptococcus gordonii clinical isolate obtained from blood cultures in a patient who was diagnosed with endocarditis in 2017. 
The bacterial isolate was grown in non-selective blood agar plates Columbia agar $+5 \%$ sheep blood (bioMérieux, Marcy l'Etoile, France) and incubated at $35^{\circ} \mathrm{C}$ under aerobic conditions in $\mathrm{CO}_{2}$ $10 \%$ atmosphere for $24 \mathrm{~h}$.

A suspension of the bacterial isolate was prepared from single colonies transferred in sterile saline to reach a concentration of $108 \mathrm{CFU} / \mathrm{mL}$, measuring optical density at $600 \mathrm{~nm}$. The suspension was than diluted by 1:100 in modified brain heart infusion (brain heart infusion broth $(37 \mathrm{~g} / \mathrm{L})$, mucin from porcine stomach type III (Sigma-Aldrich Chemie GmbH, Buchs, Switzerland) $(2.5 \mathrm{~g} / \mathrm{L})$, yeast extract $(1 \mathrm{~g} / \mathrm{L})$, L-cysteine $(0.1 \mathrm{~g} / \mathrm{L})$, sodium bicarbonate $(2 \mathrm{~g} / \mathrm{L})$ and supplemented with hemin $(5 \mathrm{mg} / \mathrm{L})$, menadione $(1 \mathrm{mg} / \mathrm{L})$, and glutamic acid $(0.25 \%))$. The $\mathrm{CFU} / \mathrm{mL}$ count was verified in by plating $100 \mu \mathrm{L}$ aliquot from serial dilutions on non-selective blood agar plates, in triplicate.

A total of $5 \mathrm{~mL}$ of the bacterial suspension, prepared as described above, was dispensed in wells of polystyrene cell culture 6-well plates (Sarstedt, Nümbrecht, Germany), each containing a couple of disks per experimental group (UNCOATED, NiT and $\mathrm{AO}$, respectively). Plates were then incubated in aerobic conditions in $\mathrm{CO}_{2} 10 \%$ atmosphere at $35^{\circ} \mathrm{C}$, with a change to fresh medium at $48 \mathrm{~h}$ intervals.

After 4 days, biofilm formed on disks was gently washed twice with PBS $(\mathrm{NaCl} 137 \mathrm{mM}$, $\mathrm{KCl} 2.7 \mathrm{mM}, \mathrm{Na} 2 \mathrm{HPO} 410 \mathrm{mM}, \mathrm{KH} 2 \mathrm{PO} 42 \mathrm{mM}, \mathrm{pH} 7.4$ ) to detach cells that were not forming part of the biofilm and to remove the culture medium.

After washing, each disk was transferred in $15 \mathrm{~mL}$ sterile tubes containing $1.5 \mathrm{~mL}$ of tryptic soy broth (TSB), supplemented with $0.1 \%$ Tween 20 (Sigma-Aldrich) and sonicated for $30 \mathrm{~min}$ in a SONICA Ultrasonic cleaner apparatus (SOLTEC, Milano, Italy). Mean cultivable cell counts per disc (CFU/disc) were then determined by plating $10 \mu \mathrm{L}$ of appropriate dilutions of the recovery medium onto tryptic soy agar (TSA) and incubating for $24 \mathrm{~h}$ at $35^{\circ} \mathrm{C}$ in $\mathrm{CO}_{2} 10 \%$. Data were obtained from 3 independent experiments, with 2 replicates per condition per experiment $[24,25]$.

\subsection{Statistical Analysis}

Statistical analysis was performed using GraphPad Prism software 8.3.1 (GraphPad Software, LLC. San Diego, CA, USA). The normality of data distribution was evaluated by means of the Kolmogorov-Smirnov test and probability plot graph. Statistical significance among different groups was determined through one-way analysis of variance (ANOVA), followed by multiple comparisons with the Tukey test, establishing a level of statistical significance for a $p$-value lower than 0.05 . The Kruskal-Wallis test, with Dunn's correction multiple comparison tests, was used to assess differences of biofilms formed on different materials.

\section{Conclusions}

Titanium discs with nitride coating or anodic oxidation treatment showed high biocompatibility with gingival fibroblasts in vitro. Furthermore, the NiT and AO disks demonstrated a reduced bacterial adhesion on their surface, compared to the untreated titanium. Further in vitro and in vivo studies are necessary to confirm these conclusions.

Author Contributions: Conceptualization, R.S. and L.L.M.; methodology, F.A. and N.C.; data analysis, G.T. and V.C.A.C.; writing - original draft preparation, K.Z.; writing-review and editing, G.T.; visualization, L.P.; supervision, F.A. All authors have read and agreed to the published version of the manuscript.

Funding: This research received no external funding.

Acknowledgments: The disks used in this study were donated by Rhein 83 s.r.l. Authors would like to thank Iolanda Adipietro, Carlotta Fanelli, Byung Chan Kim, and Andrea Bartolini for their support during laboratory analysis.

Conflicts of Interest: The authors declare no conflict of interest. 


\section{References}

1. Albrektsson, T.; Brånemark, P.I.; Hansson, H.A.; Lindström, J. Osseointegrated titanium implants. Requirements for ensuring a long-lasting, direct bone-to-implant anchorage in man. Acta Orthop. Scand. 1981, 52, 155-170. [CrossRef] [PubMed]

2. Ogle, O.E. Implant surface material, design, and osseointegration. Dent. Clin. N. Am. 2015, 59, 505-520. [CrossRef] [PubMed]

3. Romanos, G.E.; Delgado-Ruiz, R.; Sculean, A. Concepts for prevention of complications in implant therapy. Periodontol. 2000 2019, 81, 7-17. [CrossRef] [PubMed]

4. Esposito, M.; Maghaireh, H.; Grusovin, M.G.; Ziounas, I.; Worthington, H.V. Soft tissue management for dental implants: What are the most effective techniques? A Cochrane systematic review. Eur. J. Oral Implantol. 2012, 5, 221-238.

5. Abrahamsson, I.; Berglundh, T.; Glantz, P.O.; Lindhe, J. The mucosal attachment at different abutments. An experimental study in dogs. J. Clin. Periodontol. 1998, 25, 721-727. [CrossRef]

6. Niinomi, M. Recent research and development in titanium alloys for biomedical applications and healthcare goods. Sci. Technol. Adv. Mater. 2003, 4, 445. [CrossRef]

7. Zafar, M.S.; Farooq, I.; Awais, M.; Najeeb, S.; Khurshid, Z.; Zohaib, S. Bioactive surface coatings for enhancing osseointegration of dental implants. In Biomedical, Therapeutic and Clinical Applications of Bioactive Glasses; Elsevier: Amsterdam, The Netherlands, 2019; pp. 313-329.

8. Kim, Y.S.; Shin, S.Y.; Moon, S.K.; Yang, S.M. Surface properties correlated with the human gingival fibroblasts attachment on various materials for implant abutments: A multiple regression analysis. Acta Odontol. Scand. 2015, 73, 38-47. [CrossRef]

9. Tarnow, D.P.; Eskow, R.N. Preservation of implant esthetics: Soft tissue and restorative considerations. J. Esthet. Dent. 1996, 8, 12-19. [CrossRef]

10. Ferrari, M.; Cagidiaco, M.C.; Garcia-Godoy, F.; Goracci, C.; Cairo, F. Effect of different prosthetic abutments on peri-implant soft tissue. A randomized controlled clinical trial. Am. J. Dent. 2015, 28, 85-89.

11. Kim, Y.S.; Ko, Y.; Kye, S.B.; Yang, S.M. Human gingival fibroblast (HGF-1) attachment and proliferation on several abutment materials with various colors. Int. J. Oral Maxillofac. Implants 2014, 29, 969-975. [CrossRef]

12. Rath, H.; Stumpp, S.N.; Stiesch, M. Development of a flow chamber system for the reproducible in vitro analysis of biofilm formation on implant materials. PLoS ONE 2017, 12, e0172095. [CrossRef] [PubMed]

13. Cook, G.S.; Costerton, J.W.; Lamont, R.J. Biofilm formation by Porphyromonas gingivalis and Streptococcus gordonii. J. Periodontal Res. 1998, 33, 323-327. [CrossRef] [PubMed]

14. Rath, H.; Feng, D.; Neuweiler, I.; Stumpp, N.S.; Nackenhorst, U.; Stiesch, M. Biofilm formation by the oral pioneer colonizer Streptococcus gordonii: An experimental and numerical study. FEMS Microbiol. Ecol. 2017, 93. [CrossRef] [PubMed]

15. Periasamy, S.; Kolenbrander, P.E. Mutualistic biofilm communities develop with Porphyromonas gingivalis and initial, early, and late colonizers of enamel. J. Bacteriol. 2009, 191, 6804-6811. [CrossRef] [PubMed]

16. Rompen, E.; Domken, O.; Degidi, M.; Pontes, A.E.F.; Piattelli, A. The effect of material characteristics, of surface topography and of implant components and connections on soft tissue integration: A literature review. Clin. Oral Implants Res. 2006, 17, 55-67. [CrossRef] [PubMed]

17. Prachar, P.; Bartakova, S.; Brezina, V.; Cvrcek, L.; Vanek, J. Cytocompatibility of implants coated with titanium nitride and zirconium nitride. Bratisl. Lek. Listy 2015, 116, 154-156. [CrossRef]

18. Brunello, G.; Brun, P.; Gardin, C.; Ferroni, L.; Bressan, E.; Meneghello, R.; Zavan, B.; Sivolella, S. Biocompatibility and antibacterial properties of zirconium nitride coating on titanium abutments: An in vitro study. PLoS ONE 2018, 13, e0199591. [CrossRef]

19. Atsuta, I.; Ayukawa, Y.; Kondo, R.; Oshiro, W.; Matsuura, Y.; Furuhashi, A.; Tsukiyama, Y.; Koyano, K. Soft tissue sealing around dental implants based on histological interpretation. J. Prosthodont. Res. 2016, 60, 3-11. [CrossRef]

20. Violant, D.; Galofré, M.; Nart, J.; Teles, R. In vitro evaluation of a multispecies oral biofilm on different implant surfaces. Biomed. Mater. 2014, 9, 035007. [CrossRef]

21. Geng, H.; O’Neill, M.B.; Kacar, T.; Wilson, B.R.; Oren, E.E.; Sarikaya, M.; Tamerler, C. Engineered chimeric peptides with antimicrobial and titanium-binding functions to inhibit biofilm formation on Ti implants. Mater. Sci. Eng. C 2018, 82, 141-154. [CrossRef] 
22. Badran, Z.; Struillou, X.; Hughes, F.J.; Soueidan, A.; Hoornaert, A.; Ide, M. Silicon Nitride (Si3N4) Implants: The Future of Dental Implantology? J. Oral Implantol. 2017, 43, 240-244. [CrossRef] [PubMed]

23. Kumar, P.; Nagarajan, A.; Uchil, P.D. Analysis of Cell Viability by the MTT Assay. Cold Spring Harb. Protoc. 2018, 2018. [CrossRef] [PubMed]

24. Àlvarez, G.; González, M.; Isabal, S.; Blanc, V.; León, R. Method to quantify live and dead cells in multi-species oral biofilm by real-time PCR with propidium monoazide. AMB Express 2013, 3, 1. [CrossRef]

25. Giannelli, M.; Landini, G.; Materassi, F.; Chellini, F.; Antonelli, A.; Tani, A.; Zecchi-Orlandini, S.; Rossolini, G.M.; Bani, D. The effects of diode laser on Staphylococcus aureus biofilm and Escherichia coli lipopolysaccharide adherent to titanium oxide surface of dental implants. An in vitro study. Lasers Med. Sci. 2016, 31, 1613-1619. [CrossRef] [PubMed]

Publisher's Note: MDPI stays neutral with regard to jurisdictional claims in published maps and institutional affiliations.

(C) 2020 by the authors. Licensee MDPI, Basel, Switzerland. This article is an open access article distributed under the terms and conditions of the Creative Commons Attribution (CC BY) license (http://creativecommons.org/licenses/by/4.0/). 